\title{
M cell-dependent antigen uptake on follicle-associated epithelium for mucosal immune surveillance
}

\author{
Yutaka Nakamura ${ }^{1,2}$, Shunsuke Kimura ${ }^{3}$ and Koji Hase , $^{14^{*}}$
}

\begin{abstract}
The follicle-associated epithelium (FAE) covering mucosa-associated lymphoid tissue is distinct from the villous epithelium in cellular composition and functions. Interleukin-22 binding protein (IL-22BP), provided by dendritic cells at the sub-epithelial dome region, inhibits the IL-22-mediated secretion of antimicrobial peptides by the FAE. The Notch signal from stromal cells underneath the FAE diminishes goblet cell differentiation. These events dampen the mucosal barrier functions to allow luminal microorganisms to readily gain access to the luminal surface of the FAE. Furthermore, receptor activator of nucleic factor-kappa B ligand (RANKL) from a certain stromal cell type induces differentiation into microfold $(M)$ cells that specialize in antigen uptake in the mucosa. Microfold (M) cells play a key role in mucosal immune surveillance by actively transporting external antigens from the gut lumen to the lymphoid follicle. The molecular basis of antigen uptake by $\mathrm{M}$ cells has been gradually identified in the last decade. For example, GPI-anchored molecules (e.g., glycoprotein $2(\mathrm{GP} 2)$ and cellular prion protein $\left(\operatorname{PrP}^{\mathrm{C}}\right)$ ) and $\beta 1$-integrin facilitate the transport of specific types of xenobiotics. The antigen transport by $M$ cells initiates antigen-specific mucosal immune responses represented by the induction of secretory immunoglobulin A (S-lgA). Meanwhile, several invasive pathogens exploit $M$ cells as a portal to establish a systemic infection. Recent findings have uncovered the molecular machinery of differentiation and functions of $\mathrm{M}$ cells.
\end{abstract}

Keywords: FAE, M cell, Mucosal immune surveillance, Antigen uptake, Mucosa-associated lymphoid tissue (MALT), Mucosal infection

\section{Background}

Epithelial cells lining on the body surface play essential roles in various tissue functions, including respiration, digestion, reproduction, and evacuation. The epithelium is continuously exposed to external materials, which entails the risks of encountering a lot of pathogens (e.g., bacteria, viruses, and parasites) and their toxins. Indeed, various kinds of pathogens invade a host body through mucosal epithelial layers to cause infectious diseases, such as salmonellosis, hemorrhagic colitis, shigellosis, tuberculosis, influenza, and acquired immunodeficiency syndrome (AIDS). Moreover, a multitude of microbes colonize mucosal tissue, particularly human intestine,

\footnotetext{
* Correspondence: hase-kj@pha.keio.ac.jp

'Division of Biochemistry, Faculty of Pharmacy, Keio University, Tokyo

105-0011, Japan

${ }^{4}$ International Research and Development Center for Mucosal Vaccines, The Institute of Medical Science, The University of Tokyo, Tokyo 108-8639, Japan Full list of author information is available at the end of the article
}

which harbor approximately 40 trillion bacteria $[1,2]$. To deal with such a microbial burden, a unique immune system, termed "the mucosal immune system," has evolved in vertebrates. The mucosal immune system is unambiguously distinguished from the systemic immune system in terms of cellular composition, antigen recognition, and effector functions.

One of the most characteristic features of the mucosal immune system is inherent lymphoid tissue called the mucosa-associated lymphoid tissue (MALT). MALT consists of multiple or solitary lymphoid follicles covered by the follicle-associated epithelium (FAE) with a dome-like shape. These well-organized lymphoid structures are constitutively found in the intestinal and nasopharyngeal tracts and are inducible in the bronchial tissue [3]. The systemic lymphoid tissue, namely the spleen and peripheral lymph nodes, activates the immune response to antigens from the blood vessels and afferent vessels, 
respectively. Meanwhile, MALT directly takes up antigens from the lumen across the FAE to induce the mucosal immune response. Thus, the mucosal immune system continuously monitors exogenous antigens on the mucosal surface for immune surveillance.

The antigen internalization via the FAE was initially found by Kenzaburo Kumagai in 1922 [4]. However, the cellular entity responsible for the antigen transport had been unclear for half a century since the finding, mainly owing to technical difficulties. In the 1970s, by taking advantage of the development of electron microscopy, Max Cooper found the specialized epithelial cells that play a key role in the antigen uptake in the FAE in the bursa of Fabricius [5]. Concomitantly, Robert Owen revealed a similar cell type in human Peyer's patches and named it microfold (M) cells [6, 7]. It is well known that antigen uptake through microfold $(\mathrm{M})$ cells contributes to the induction of antigen-specific immunoglobulin A (IgA), a dominant isotype in secretory fluids of most mucosal tissues, except for the respiratory and genital tract [8]. IgA secreted into the mucosal lumen binds to luminal commensal and pathogenic microbes to prevent microbial adhesion to epithelial cells. Therefore, antigen uptake by $\mathrm{M}$ cells is considered to be critical for the onset of the mucosal immune response. Recent studies have uncovered the molecular basis of differentiation and functions of $M$ cells. In this review, we discuss current knowledge of development and antigen uptake in the FAE and M cells.

\section{Formation of Peyer's patches and the FAE}

Formation of MALT, especially Peyer's patches (PP), during developmental stages has been well documented. Anlagen of mouse PPs are found at 15 days postcoitus in mice [9]. In the primordial PPs, lymphotoxin $\alpha_{1} \beta_{2}$ $\left(\mathrm{LT} \alpha_{1} \beta_{2}\right)$-expressing lymphoid tissue inducer (LTi) cells stimulate LT $\beta R$-expressing lymphoid tissue organizer (LTo) cells to produce chemokines (e.g., CXCL13) and adhesion molecules (e.g., VCAM-1) involved in the recruitment and organization of lymphocytes [10]. At embryonic day 17.5 (E17.5), the dome-shaped FAE is established, and it produces CCL20 to attract

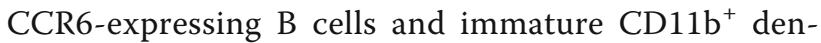
dritic cells [11-13]. Transcriptome analysis illustrated a distinct gene expression profile between the FAE and the villous epithelium [14]. Remarkably, several chemokines (Ccl6, Ccl9, Ccl20, Ccl26, and Cxcl16) are highly upregulated in the FAE [15-17]. Expressions of these chemokines are mainly controlled by signaling through the LT $\beta R$ and receptor activator of nucleic factor-kappa B (RANK; TNFRSF11A). Genetic ablation of RANK signaling diminishes Ccl20 expression in gut-associated lymphoid tissue (GALT) [18]. In human, the clusters of lymphocytes are identified in small intestine at 14-16 weeks of gestation, and PPs are microscopically observable at gestational age of 24 weeks [19]. After birth, human PPs greatly expand early in life $[19,20]$.

The FAE in PP is formed at the late stage of fetal development as described above. We previously reported that LTo cell-mediated activation of epithelial Notch signaling contributes to the organization and integrity of the FAE [21]. Activation of epithelial Notch signaling suppresses goblet cell differentiation as described below and secures CCL20 expression in the FAE, facilitating full maturation of PPs and isolated lymphoid follicles. The maturation of MALT also necessitates antigen transport via $M$ cells. In support of this idea, mice lacking $M$ cells because of deficiency in RANK in intestinal epithelium or nucleic factor-kappa B ligand (RANKL) in sub-epithelial mesenchymal cells [known as $M$ cell inducer (MCi)] of GALTs display the reduced size of PPs in association with inactivation of the germinal center reaction $[18,22]$. Thus, FAE-intrinsic Notch signaling as well as antigen exposure is essential for the maturation of GALTs. Luminal antigens are also indispensable for the establishment of the overall mucosal immune system. Antigen-free mice that are raised and bred on an elemental diet, devoid of dietary antigens under germ-free conditions, exhibited a marked reduction of lymphocytes in the small intestinal lamina propria and mesenteric lymph nodes, but not in the spleen [23].

\section{Characterization of the FAE}

Intestinal epithelial cells constitute a front-line barrier for the prevention of invasive microorganisms. For instance, intercellular tight junctions provide a robust physical barrier by securing close connections between adjacent cells [24]. Polymeric immunoglobulin receptor (pIgR) expressed on the basolateral plasma membrane of epithelial cells transports dimeric IgA to the lumen [25]. Furthermore, Atoh1/Math $1^{+}$intestinal secretory cell lineages, such as goblet cells, play central roles in the establishment of physicochemical barriers by secreting mucin [26]. These molecules are a prerequisite for segregation of microbial habitats from the epithelial surface [27]. In sharp contrast to the ordinary villous epithelium, the FAE is mainly composed of enterocytes and $M$ cells with a limited number of goblet cells. The mucin layer is therefore thinner in the FAE region than in the villous region [28]. The hypoplastic mucin layer allows luminal antigens to readily gain access to the FAE (Fig. 1).

The differentiation of goblet cells is controlled by the Notch signal that is widely utilized for cell-cell interaction in various cell types [26]. In the intestinal villi, secretory-type epithelial cells express Notch ligands (e.g., Dll1) to bind Notch receptors in adjacent epithelial cells $[29,30]$. The ligation of the ligands liberates the Notch 


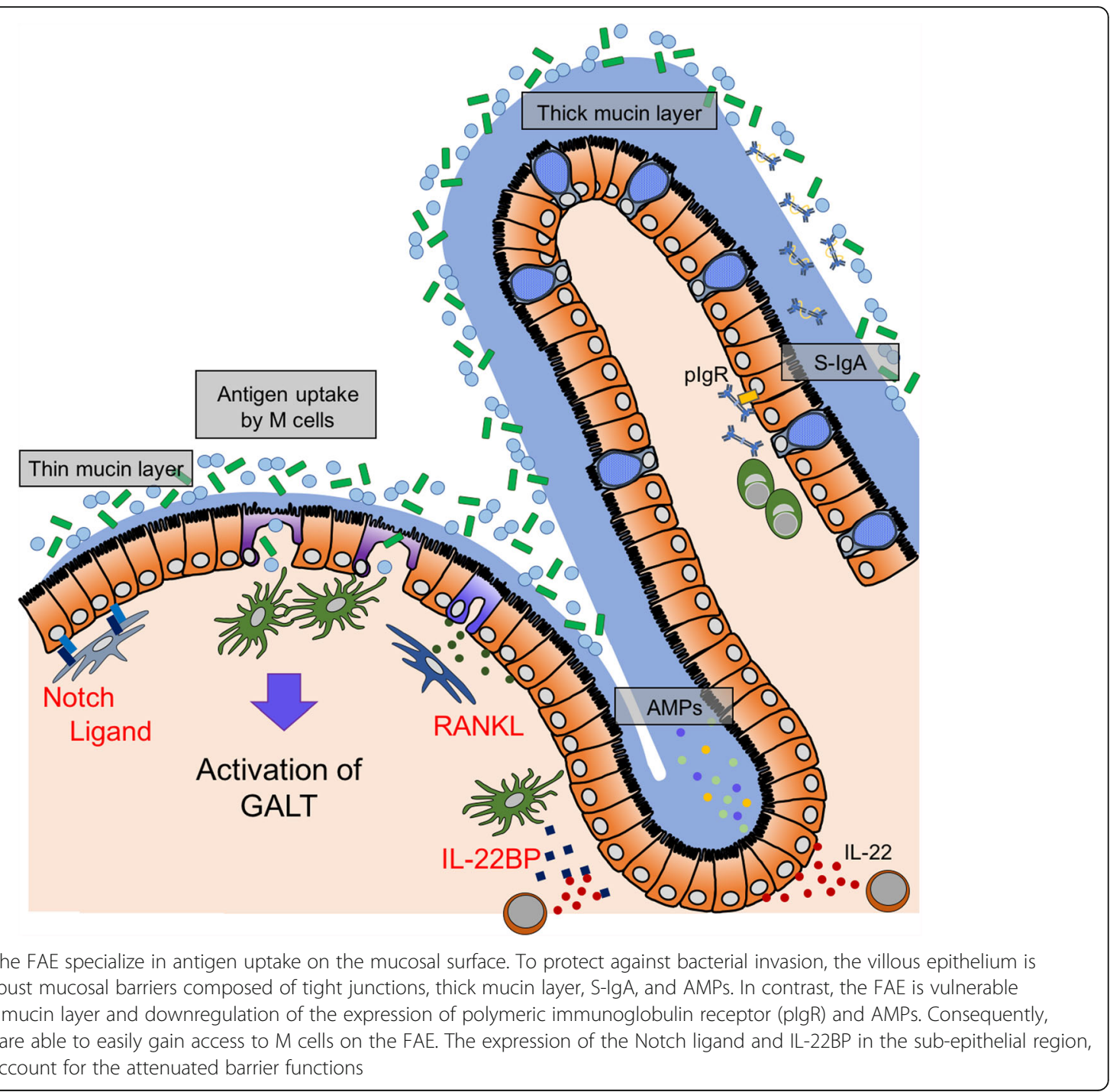

intracellular domain (NICD), which translocates into the nucleus to form a transcriptional activator complex with the recombination signal binding protein for immunoglobulin $\mathrm{K} J$ region (RBP-J). The NICD/RBP-J complex upregulates the expression of Hes1, which in turn represses the expression of Atoh1, the main regulator of secretory cell lineages $[26,31,32]$. Consequently, activation of the Notch signal in intestinal epithelial cells limits the number of secretory cells and maintains the balance between absorptive and secretory epithelial cell populations. Such self-regulation of epithelial cell populations in the intestine is termed lateral inhibition. In PPs, stromal cells beneath the FAE constitutively express a Notch ligand, Dll1 [21, 33], indicating that secretory cell lineages in the FAE are suppressed by stromal Notch ligands (Fig. 1). The inactivation of the Notch signal by genetic ablation of RBP-J in intestinal epithelial cells $\left(\mathrm{RBP}-\mathrm{J}^{\triangle \mathrm{IEC}}\right)$ markedly increases the number of goblet cells in both the FAE and villous epithelium [21]. As a consequence, RBP-J ${ }^{\triangle I E C}$ mice are defective in maturation of PPs and isolated lymphoid follicles at least partly because of downregulated expression of CCL20, which is mainly produced by enterocytes, but not goblet cells, during the developmental stage.

In addition, Paneth cells abundantly produce antimicrobial products (AMPs) like lysozyme, RegIII $\gamma$, and $\alpha$-defensins (cryptdins) in response to cholinergic nerve activation and stimuli with microbial products [34, 35]. Enterocytes in the intestinal villi also produce AMPs, such as RegIII $\gamma$ and $\beta$-defensins [34, 36, 37]. However, the expression of the AMPs remarkably decreases in the FAE as compared with the villus epithelium. Interleukin-22 (IL-22), produced by type 3 innate lymphoid cells (ILC3) and $\mathrm{T}$ helper 17 (Th17) cells in the lamina propria, upregulates the expression of AMPs [38, 39]. IL-22 signaling is ameliorated in the FAE. This is attributed to constitutive 
expression of IL-22-binding protein (IL-22BP), a secreted decoy receptor for IL-22, which is abundantly provided by immature dendritic cells at the SED of PPs [40] (Fig. 1). Expression of pIgR is also downregulated in the FAE [41], although the underlying mechanism remains to be clarified. Collectively, the cellular components of PPs, namely epithelial cells, dendritic cells, and stromal cells, are responsible for the establishment of a specialized microenvironment that facilitates uptake of mucosal antigens.

\section{Differentiation of $M$ cells}

$\mathrm{M}$ cells account for approximately $10 \%$ of FAE cells in mouse PPs (Fig. 2a) [28]. M cells can be identified by electron microscopy owing to their characteristic morphology: sparse and irregular microvilli, called microfold, as well as an invaginated basal plasma membrane to form the pocket-like structure that is occupied by immunocompetent cells $[5,6]$. Although $M$ cells were anatomically identified in the 1970s, technical difficulties in isolation and culture of $\mathrm{M}$ cells had hampered further analyses to elucidate their differentiation and functions. To deal with this issue, we previously established a method to isolate the FAE and successfully performed transcriptome analysis followed by in situ hybridization to determine $M$ cell-specific molecules [14, 42]. Consequently, the course of analysis led to the identification of several M cell-specific markers including CCL9, Sgne-1, and GP2. Furthermore, recent progress uncovered the key molecules that govern the differentiation of M cells. Williams and colleagues revealed that RANKL (TNFSF11) is essential for the differentiation of $M$ cells [43]. As described earlier, RANKL is provided from stromal MCi cells residing underneath the FAE of GALT (Fig. 2) [18]. Because intestinal epithelial cells constitutively express a RANKL receptor, RANK (TNFRSF11A), intraperitoneal administration of recombinant RANKL ectopically induces differentiation of the $\mathrm{M}$ cell-like $\mathrm{GP}^{+}$cells in the intestinal villous region $[43,44]$. Of note, $M$ cells scattered in the intestinal villi of RANKL-treated mice and the FAE of untreated mice, suggesting existence of potential machinery to regulate the number of $\mathrm{M}$ cells. Because we observed that deficiency in RBP-J did not increase the number of $\mathrm{M}$ cells (Hase $\mathrm{K}$ et al., unpublished observation), lateral inhibition via Notch signaling should be excluded in the regulation of $\mathrm{M}$ cell number.

The stimulation with RANKL activates NF- $k B$ family in both canonical (NF-kB1 p50, RelA, and c-Rel) and non-canonical (NF-kB2 p52 and RelB) pathways [45]. The RANKL treatment in aly/aly mice carrying a point mutation of NF-kB inducing kinase (NIK) gene failed to induce $M$ cells in the intestinal villi [46, 47]. Because NIK acts as a specific component of the non-canonical NF- $\mathrm{kB}$ pathway [48], this result suggested that the RANKL-induced non-canonical NF- $\mathrm{kB}$ pathway is essential for $\mathrm{M}$ cell differentiation. Recent studies reported that $\mathrm{M}$ cell differentiation was dependent on non-canonical RelB pathway, but not canonical c-Rel [46, 47, 49]. However, the canonical NF-kB pathway supports $\mathrm{M}$ cell differentiation by enhancing the expression of Relb and $N f k b 2$ in enteroids stimulated with TNF- $\alpha$ [47].

Over the course of differentiation, $M$ cells differentially express several molecular markers [50-52], suggesting that $M$ cells undergo stepwise maturation processes (Fig. 2b). This concept was supported by a current single-cell transcriptome analysis that clearly demonstrated molecular signatures of early and late $\mathrm{M}$ cell progenitors, and immature and fully mature $\mathrm{M}$ cells [53].

Indeed, Marcksl1 and Anx5 are expressed in M cell progenitors and villus epithelial cells immediately after intraperitoneal treatment with RANKL $[44,53]$. In contrast, Spi-B, Ccl9, and Tnfaip2 (also termed M-sec) were recognized as immature $M$ cell makers [53]. Among these molecules, Spi-B plays a pivotal role in the development of fully differentiated M cells. Glycoprotein-2 (GP2)-positive mature $M$ cells are absent in PPs of $\mathrm{Spib}^{-1-}$ mice, whereas Marcksl1 ${ }^{+} \mathrm{AnnexinV}^{+}$immature $\mathrm{M}$ cells are intact [44]. Furthermore, Spib ${ }^{-1-}$ mice reveal much less uptake of pathogenic bacteria, such as Salmonella enterica serovar Typhimurium (Salmonella Typhimurium) and Yersinia enterocolitica [44]. Collectively, the nuclear translocation of RelB and the expression of transcription factor Spi-B are essential for the RANKL-induced differentiation of M cells. In contrast, the commensal bacteria Alcaligenes can be internalized into GALT of $\mathrm{Spib}^{-/-}$mice $[54,55]$, indicating that immature $\mathrm{M}$ cells may take up this $\mathrm{PP}$-colonizing bacteria. Alternatively, the epithelial cell-independent trans-epithelial antigen sampling by mononuclear phagocytes may mediate the internalization of Alcaligenes in PPs [56]. This observation implies that antigen uptake of certain bacteria in the FAE does not always necessitate mature $\mathrm{M}$ cells.

\section{Antigen uptake receptors in $\mathbf{M}$ cells}

Recent studies demonstrated that $M$ cells utilize several receptors to recognize and transport specific luminal antigens. GP2 is a GPI-anchored protein expressed on the apical surface of $\mathrm{M}$ cells to function as an uptake receptor for type I pili-expressing bacteria (e.g., S. Typhimurium and Escherichia coli) (Fig. 3) [42]. GP2 also binds hemagglutinin A1 of botulinum neurotoxin, increasing susceptibility to botulism [57]. M cells highly express other GPI-anchored membrane proteins, cellular prion protein $\left(\mathrm{PrP}^{\mathrm{C}}\right)$ and uromodulin (Umod)/Tamm-Horsfall protein (THP), which serve as uptake receptors for Brucella abortus and Lactobacillus acidophilus, respectively $[55,58,59]$. In addition, $\beta_{1}$-integrin localized on the apical surface of $\mathrm{M}$ cells facilitates transcytosis of Yersinia spp. [58, 60] (Fig. 3). These observations illustrate that 

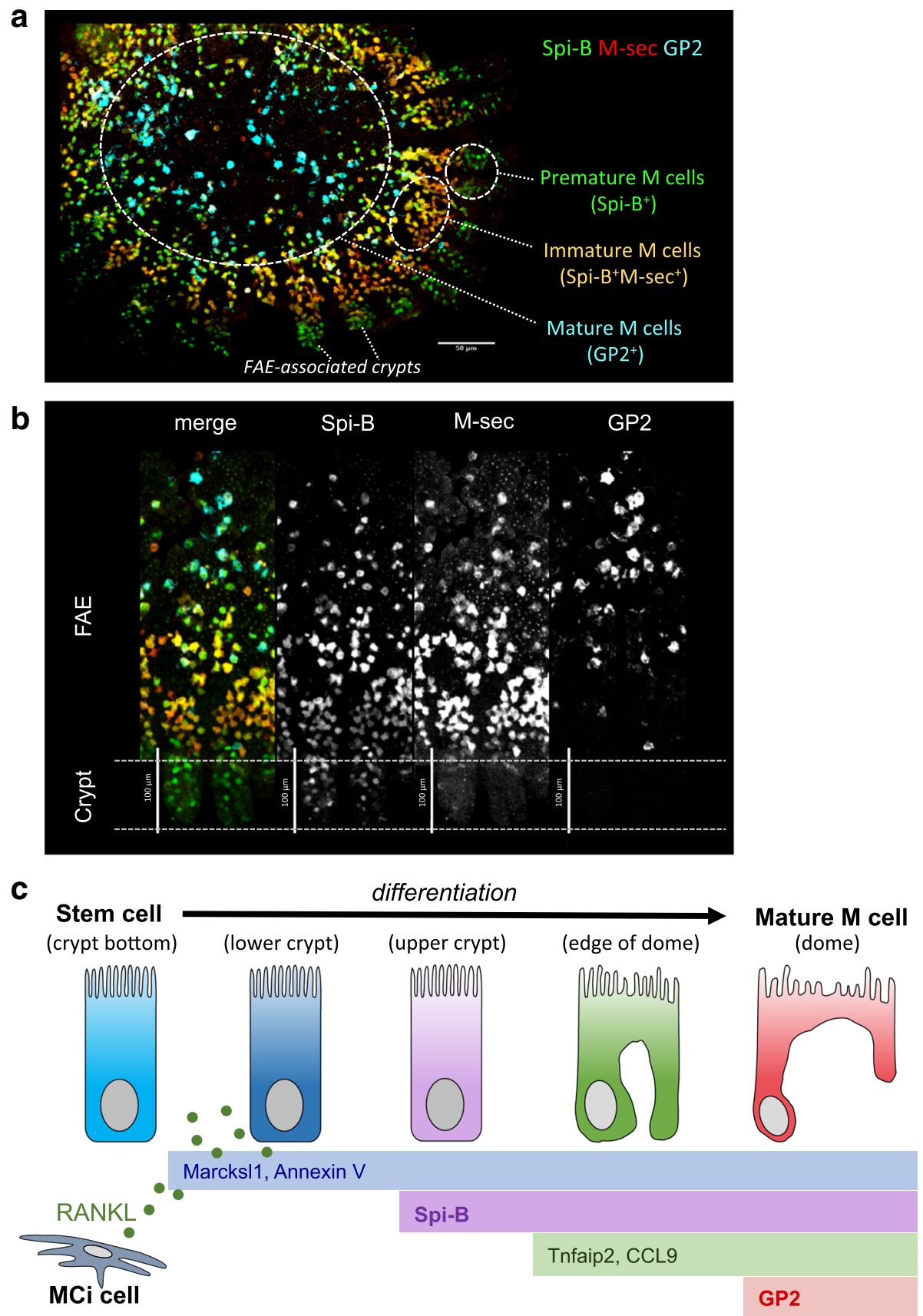

Fig. 2 Expression of M cell marker molecules during differentiation. a Fluorescence in situ hybridization (FISH) image of Spib, M-Sec, and Gp2 in a mouse FAE specimen is shown. Premature and immature $M$ cells are observed at the crypt and the periphery of dome region, respectively, whereas fully mature $\mathrm{M}$ cells are found at the middle and upper dome region. $\mathbf{b}$ Enlarged images of the cypt region are shown. $\mathbf{c}$ RANKL from stromal M cell inducer (MCi) cells stimulates intestinal stem cells to initiate M cell differentiation. Early (Marksl1, AnnexinV), intermediate (Spi-B, Tnfaip2, CCL9), and mature (GP2) markers are serially expressed during the course of differentiation

M cells express multiple receptors on their apical plasma membrane to efficiently take up certain microbes. Although the uptake receptors have been extensively analyzed during this decade, the intracellular trafficking machinery regulating the antigen transcytosis remains largely unknown. A current study revealed that Allograft inflammation factor 1 (Aif1), which is known to be involved in phagocytosis in macrophages [61], is specifically upregulated in $M$ cells among intestinal epithelial cells. Aif1 plays a non-redundant role in the activation of $\beta_{1}$-integrin and facilitates the uptake of $Y$. enterocolitica [60]. Furthermore, transcriptome analysis of $M$ cells 


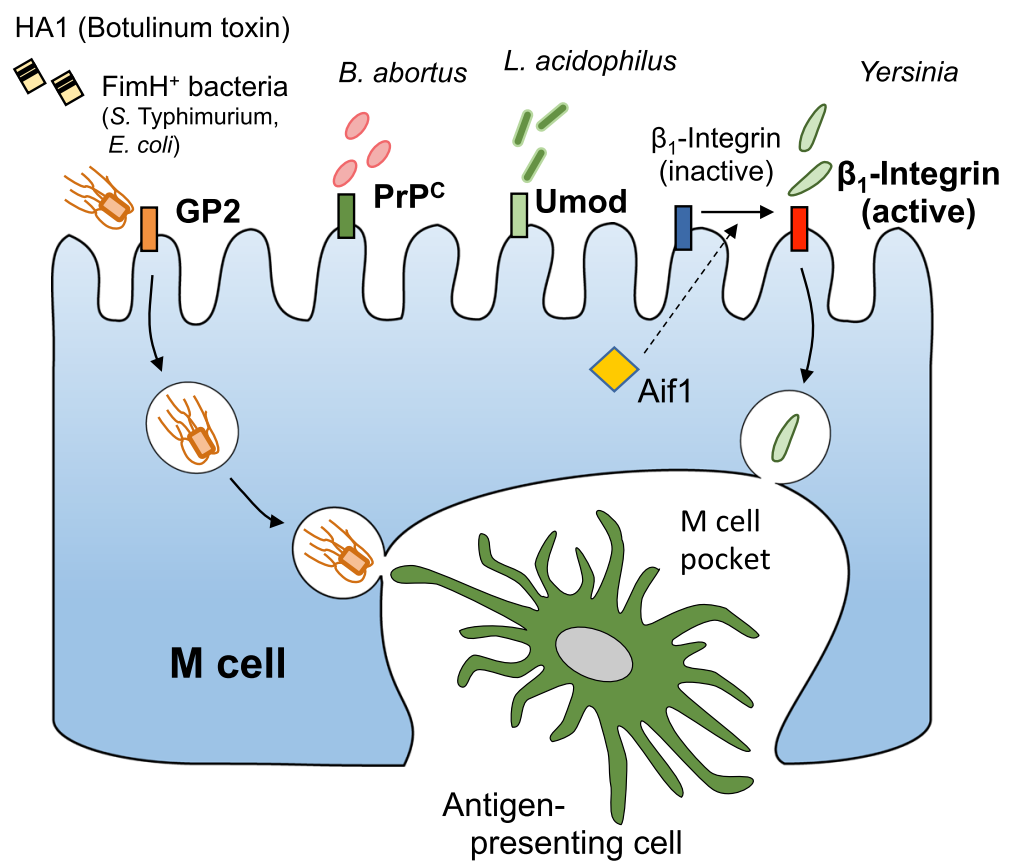

Fig. 3 Antigen uptake receptors on the apical surface of M cells. GP2 binds to the HA1 domain of the botulinum toxin and FimH $\mathrm{H}^{+}$type 1 pili of certain bacterial species. PrPC facilitates internalization of Brucella abortus into M cells. Umod serves as an uptake receptor for Lactobacillus acidophilus. $\beta_{1}$-integrin is activated by Aif1 to function as an uptake receptor for Yersinia spp. Antigens taken up by $\mathrm{M}$ cells are transcytosed to an M cell pocket, whereby antigen-presenting cells, like dendritic cells, capture the antigens

demonstrated that $\mathrm{M}$ cells abundantly express a substantial number of intracellular molecules, potentially contributing to vesicular transport or actin remodeling during the course of the transcytotic pathway [53]. Functional analyses of these molecules should open up a new research direction on the molecular mechanism of $\mathrm{M}$ cell-specific antigen transport.

\section{$M$ cell as a portal for infectious agents}

Several invasive bacteria are known to exploit $M$ cells to invade the host body. S. Typhimurium and Shigella spp. gain entry to Peyer's patches through $M$ cells [62-64]. Furthermore, $M$ cells take up scrapie prion protein $\left(\mathrm{PrP}^{\mathrm{Sc}}\right)$ from food and thus potentially contribute to the accumulation of $\operatorname{PrP}^{\mathrm{Sc}}$ in follicular dendritic cells of PPs [65]. The deletion of $M$ cells moderates the pathogenesis of prion's disease [66]. In addition to the foodborne pathogens, the airborne pathogen Mycobacterium tuberculosis also invades the host body via $\mathrm{M}$ cells in nasopharynx-associated lymphoid tissues (NALTs) and bronchus-associated lymphoid tissues (BALTs) [67]. These findings indicate that $M$ cells function as an initial step of both mucosal immunity and pathogenesis, and this character is often referred to as the "double-edged sword" [68].

However, little is known about whether M cell-dependent antigen uptake predominantly contributes to immune responses against infection or bacterial invasion. Our current study reveals that $\mathrm{M}$ cell-null mice are highly susceptible to the mucosal infection of non-invasive pathogens, indicating that $\mathrm{M}$ cell-mediated antigen transport is important for the host defenses against, at least, non-invasive pathogens (Nakamura et al. unpublished observation). Recent studies have revealed that gastrointestinal microbiota is implicated in the development of multiple diseases, such as diabetes, obesity, multiple sclerosis, and autism spectrum disorder [69]. There is an open question whether $M$ cell-mediated antigen transport and the subsequent immune response could regulate the commensal microbiota. Further investigations may uncover novel links among $\mathrm{M}$ cells, mucosal immunity, and the gut microbiota.

\section{Conclusion}

Recent findings have provided new insights into the molecular basis of antigen transport on the mucosal surface. In particular, identification of receptors specific for pathogens and/or commensals on $\mathrm{M}$ cells exemplify selective uptake of particular antigens for mucosal immunosurveillance. Because $M$ cell-mediated antigen uptake contributes to the induction of antigen-specific secretory immunoglobulin A (S-IgA), the uptake receptors on M cells may be a promising target for mucosal vaccination to efficiently induce pathogen-specific S-IgA [70-72]. S-IgA not only suppresses pathogenic infection but also shapes the gut microbial community. Alteration of the gut microbial composition is a predisposing factor for various 
diseases including diabetes, obesity, non-alcoholic steatohepatitis, multiple sclerosis, and autism spectrum disorder [69]. It is therefore intriguing to evaluate the role of $M$ cells in the regulation of the gut microbiota, as well as the development of the diseases associated with dysbiosis. Further investigation employing $M$ cell-null mice will shed light on the biological significance of $\mathrm{M}$ cells.

\begin{abstract}
Abbreviations
AIDS: Acquired immunodeficiency syndrome; Aif1: Allograft inflammation factor 1; AMPs: Antimicrobial proteins; BALT: Bronchus-associated lymphoid tissue; FAE: Follicle-associated epithelium; GALT: Gut-associated lymphoid tissue; GP2: Glycoprotein 2; IgA: Immunoglobulin A; IL-22: Interleukine-22; IL22BP: Interleukine-22 binding protein; ILC3: Type 3 innate lymphoid cell; LTi: Lymphoid tissue inducer; LTo: Lymphoid tissue organizer;

$\mathrm{LTa}_{1} \beta_{2}$ : Lymphotoxin $a_{1} \beta_{2} ;$ M cell: Microfold cell; MALT: Mucosa-associated lymphoid tissue; MCi cell: Microfold cell inducer cell; NALT: Nose-associated lymphoid tissue; NICD: Notch intracellular domain; NIK: NF-KB inducing kinase; plgR: Polymeric immunoglobulin receptor; PP: Peyer's patch; $\operatorname{PrP}^{C}$ : Cellular prion protein; $\mathrm{PrP}^{\mathrm{SC}}$ : Scrapie prion protein; RANK: Receptor activator of nucleic factor-kappa B; RANKL: Receptor activator of nucleic factor-kappa B ligand; RBP-J: Recombination signal binding protein for immunoglobulin $\mathrm{K} J$ region; S-lgA: Secretory immunoglobulin A; Th17: T helper 17; THP: Tamm-Horsfall protein; Umod: Uromodulin
\end{abstract}

\section{Acknowledgements}

This work was supported partly by the Grants from the Joint Research Project of the Institute of Medical Science, the University of Tokyo (K.H.), and the Joint Research Program of the Institute for Genetic Medicine, Hokkaido University (K.H.)

\section{Funding}

This work was funded by JSPS KAKENHI (Grant number: $17 \mathrm{H04089}$ to KH), MEXT KAKENHI (Grant numbers: $16 \mathrm{H} 01369$ and 26116709 to KH), AMED-Crest $(\mathrm{KH})$, Takeda Science Foundation $(\mathrm{KH})$, and The NOVARTIS Foundation JAPAN for Promotion of Science $(\mathrm{KH})$

\section{Authors' contributions}

YN and $\mathrm{KH}$ wrote the manuscript. SK provided the immunofluorescence staining data. All authors read and approved the final manuscript.

\section{Ethics approval and consent to participate}

Not applicable.

\section{Competing interests}

The authors declare that they have no competing interests.

\section{Publisher's Note}

Springer Nature remains neutral with regard to jurisdictional claims in published maps and institutional affiliations.

\section{Author details}

${ }^{1}$ Division of Biochemistry, Faculty of Pharmacy, Keio University, Tokyo 105-0011, Japan. ${ }^{2}$ Graduate School of Medicine, The University of Tokyo, Tokyo 108-8639, Japan. ${ }^{3}$ Laboratory of Histology and Cytology, Graduate School of Medicine, Hokkaido University, Sapporo 060-8638, Japan. ${ }^{4}$ International Research and Development Center for Mucosal Vaccines, The Institute of Medical Science, The University of Tokyo, Tokyo 108-8639, Japan.

Received: 29 March 2018 Accepted: 28 May 2018

Published online: 03 September 2018

\section{References}

1. Savage DC. Microbial ecology of the gastrointestinal tract. Annu Rev Microbiol. 1977;31:107-33.

2. Sender R, Fuchs $\mathrm{S}$, Milo R. Revised estimates for the number of human and bacteria cells in the body. PLoS Biol. 2016;14:e1002533.

3. Moyron-Quiroz JE, Rangel-Moreno J, Kusser K, Hartson L, Spraque F, Goodrich S, Woodland DL, Lund FE, Randall TD. Role of inducible bronchus associated lymphoid tissue (iBALT) in respiratory immunity. Nat Med. 2004 10:927-34.

4. Kumagai K. Keitaitekiseibun no tyoukan kyusyu kikou ni tsuite (Japanese). Osaka igakukai. 1922;21:497-522.

5. Bockman DE, Cooper MD. Pinocytosis by epithelium associated with lymphoid follicles in the bursa of Fabricius, appendix, and Peyer's patches. An electron microscopic study. Am J Anat. 1973;136:455-77.

6. Owen RL, Jones AL. Epithelial cell specialization within human Peyer's patches: an ultrastructural study of intestinal lymphoid follicles. Gastroenterology. 1974;66:189-203.

7. Owen RL. Sequential uptake of horseradish peroxidase by lymphoid follicle epithelium of Peyer's patches in the normal unobstructed mouse intestine: an ultrastructural study. Gastroenterology. 1977;72:440-51.

8. Woof JM, Mestecky J. Mucosal immunoglobulins. Immunol Rev. 2005;206: 64-82.

9. Hashi H, Yoshida H, Honda K, Fraser S, Kubo H, Awane M, Takabayashi A, Nakano H, Yamaoka Y, Nishikawa S-I. Compartmentalization of Peyer's patch anlagen before lymphocyte entry. J Immunol. 2001;166:3702-9.

10. Luther SA, Ansel KM, Cyster JG. Overlapping roles of CXCL13, interleukin 7 receptor $a$, and CCR7 ligands in lymph node development. J Exp Med. 2003:197:1191-8.

11. McDonald KG, McDonough JS, Wang C, Kucharzik T, Williams IR, Newberry RD. CC chemokine receptor 6 expression by B lymphocytes is essential for the development of isolated lymphoid follicles. Am J Pathol. 2007;170:122940.

12. Rumbo M, Sierro F, Debard N, Kraehenbuhl J-P, Finke D. Lymphotoxin beta receptor signaling induces the chemokine CCL20 in intestinal epithelium. Gastroenterology. 2004;127:213-23.

13. Iwasaki A, Kelsall BL. Localization of distinct Peyer's patch dendritic cell subsets and their recruitment by chemokines macrophage inflammatory protein (Mip)-3a, Mip-3 $\beta$, and secondary lymphoid organ chemokine. J Exp Med. 2000:191:1381-94.

14. Hase K. Distinct gene expression profiles characterize cellular phenotypes of follicle-associated epithelium and M cells. DNA Res. 2005:12:127-37.

15. Mabbott NA, Donaldson DS, Ohno H, Williams IR, Mahajan A. Microfold (M) cells: important immunosurveillance posts in the intestinal epithelium. Mucosal Immunol. 2013;6:666-77.

16. Hase K, Murakami T, Takatsu H, Shimaoka T, limura M, Hamura K, Kawano K, Ohshima S, Chihara R, Itoh K, Yonehara S, Ohno H. The membrane-bound chemokine CXCL16 expressed on follicle-associated epithelium and M cells mediates lympho-epithelial interaction in GALT. J Immunol. 2006;176:43-51.

17. Zhao X, Sato A, Cruz Dela CS, Linehan M, Luegering A, Kucharzik T, Shirakawa A-K, Marquez G, Farber JM, Williams I, Iwasaki A. CCL9 is secreted by the follicle-associated epithelium and recruits dome region Peyer's patch CD11 b ${ }^{+}$dendritic cells. J Immunol. 2003:171:2797-803.

18. Nagashima K, Sawa S, Nitta T, Tsutsumi M, Okamura T, Penninger JM, Nakashima T, Takayanagi H. Identification of subepithelial mesenchymal cells that induce IgA and diversify gut microbiota. Nat Immunol. 2017;18: 675-82.

19. Jung C, Hugot J-P, Barreau F. Peyer's patches: the immune sensors of the intestine. Int J Inflam. 2010;2010:823710-2.

20. Cornes JS. Number, size, and distribution of Peyer's patches in the human small intestine: part I the development of Peyer's patches. Gut. 1965:6:225.

21. Obata Y, Kimura S, Nakato G, lizuka K, Miyagawa Y, Nakamura Y, Furusawa $Y$, Sugiyama M, Suzuki K, Ebisawa M, Fujimura Y, Yoshida H, Iwanaga T, Hase K, Ohno $\mathrm{H}$. Epithelial-stromal interaction via notch signaling is essential for the full maturation of gut-associated lymphoid tissues. EMBO Rep. 2014;15: 1297-304.

22. Rios D, Wood MB, Li J, Chassaing B, Gewirtz AT, Williams IR. Antigen sampling by intestinal $M$ cells is the principal pathway initiating mucosal IgA production to commensal enteric bacteria. Mucosal Immunol. 2016;9: 907-16.

23. Kim KS, Hong S-W, Han D, Yi J, Jung J, Yang B-G, Lee JY, Lee M, Surh CD. Dietary antigens limit mucosal immunity by inducing regulatory $T$ cells in the small intestine. Science. 2016;351:858-63.

24. Tsukita S, Furuse M, Itoh M. Multifunctional strands in tight junctions. Nat Rev Mol Cell Biol. 2001;2:285.

25. Rojas R, Apodaca G. Immunoglobulin transport across polarized epithelial cells. Nat Rev Mol Cell Biol. 2002;3:944.

26. Yang Q. Requirement of Math1 for secretory cell lineage commitment in the mouse intestine. Science. 2001;294:2155-8. 
27. Johansson MEV, Phillipson M, Petersson J, Velcich A, Holm L, Hansson GC. The inner of the two Muc2 mucin-dependent mucus layers in colon is devoid of bacteria. Proc Natl Acad Sci U S A. 2008;105:15064-9.

28. Ohno H. Intestinal M cells. J Biochem. 2016;159:151-60.

29. van Es JH, Sato T, van de Wetering M, Lyubimova A, Gregorieff A, Zeinstra L, van den Born M, Korving J, Martens ACM, van den Oudenaarden A, Clevers H. Dll1 ${ }^{+}$secretory progenitor cells revert to stem cells upon crypt damage. Nat Cell Biol. 2012;14:1099-104.

30. Sancho R, Cremona CA, Behrens A. Stem cell and progenitor fate in the mammalian intestine: notch and lateral inhibition in homeostasis and disease. EMBO Rep. 2015;16:571-81.

31. Fre $S$, Huyghe M, Mourikis P, Robine S, Louvard D, Artavanis-Tsakonas S. Notch signals control the fate of immature progenitor cells in the intestine. Nature. 2005;435:964-8.

32. van Es JH, van Gijn ME, Riccio O, van den Born M, Vooijs M, Begthel $H$, Cozijnsen M, Robine S, Winton DJ, Radtke F, Clevers H. Notch/Y-secretase inhibition turns proliferative cells in intestinal crypts and adenomas into goblet cells. Nature. 2005;435:959-63.

33. Mach J, Hshieh T, Hsieh D, Grubbs N, Chervonsky A. Development of intestinal M cells. Immunol Rev. 2005;206:177-89.

34. Ayabe T, Satchell DP, Wilson CL, Parks WC, Selsted ME, Ouellette AJ. Secretion of microbicidal a-defensins by intestinal Paneth cells in response to bacteria. Nat Immunol. 2000;1:113.

35. Cash HL, Whitham CV, Behrendt CL, Hooper LV. Symbiotic bacteria direct expression of an intestinal bactericidal lectin. Science. 2006;313:1126-30.

36. O'Neil DA, Porter EM, Elewaut D, Anderson GM, Eckmann L, Ganz T, Kagnoff MF. Expression and regulation of the human $\beta$-defensins hBD-1 and hBD-2 in intestinal epithelium. J Immunol. 1999;163:6718-24.

37. Gallo RL, Hooper LV. Epithelial antimicrobial defence of the skin and intestine. Nat Rev Immunol. 2012;12:503-16.

38. Artis D, Spits H. The biology of innate lymphoid cells. Nature. 2015;517:293-301.

39. Zheng Y, Valdez PA, Danilenko DM, Hu Y, Sa SM, Gong Q, Abbas AR, Modrusan Z, Ghilardi N, de Sauvage FJ, Ouyang W. Interleukin-22 mediates early host defense against attaching and effacing bacterial pathogens. Nat Med. 2008;14:282-9.

40. Jinnohara T, Kanaya T, Hase K, Sakakibara S, Kato T, Tachibana N, Sasaki T, Hashimoto $Y$, Sato T, Watarai $H$, Kunisawa J, Shibata N, Williams IR, Kiyono $\mathrm{H}$, Ohno H. IL-22BP dictates characteristics of Peyer's patch follicle-associated epithelium for antigen uptake. J Exp Med. 2017;214: 1607-18.

41. Bjerke K, Brantzaeg P. Lack of relation between expression of HLA-DR and secretory component (SC) in follicle-associated epithelium of human Peyer's patches. Clin Exp Immunol. 1988;71:502.

42. Hase K, Kawano K, Nochi T, Pontes GS, Fukuda S, Ebisawa M, Kadokura K, Tobe T, Fujimura Y, Kawano S, Yabashi A, Waguri S, Nakato G, Kimura S, Murakami T, limura M, Hamura K, Fukuoka S-I, Lowe AW, Itoh K, Kiyono H, Ohno $\mathrm{H}$. Uptake through glycoprotein 2 of $\mathrm{FimH}^{+}$bacteria by $\mathrm{M}$ cells initiates mucosal immune response. Nature. 2009;462:226-30.

43. Knoop KA, Kumar N, Butler BR, Sakthivel SK, Taylor RT, Nochi T, Akiba H, Yagita $H$, Kiyono $H$, Williams IR. RANKL is necessary and sufficient to initiate development of antigen-sampling M cells in the intestinal epithelium. J Immunol. 2009;183:5738-47.

44. Kanaya T, Hase K, Takahashi D, Fukuda S, Hoshino K, Sasaki I, Hemmi H, Knoop KA, Kumar N, Sato M, Katsuno T, Yokosuka O, Toyooka K, Nakai K, Sakamoto A, Kitahara Y, Jinnohara T, McSorley SJ, Kaisho T, Williams IR, Ohno $\mathrm{H}$. The Ets transcription factor Spi-B is essential for the differentiation of intestinal microfold cells. Nat Immunol. 2012;13:729-36.

45. Vallabhapurapu S, Karin M. Regulation and function of NF-kappaB transcription factors in the immune system. Annu Rev Immunol. 2009;27: 693-733.

46. Kimura S, Yamakami-Kimura M, Obata Y, Hase K, Kitamura H, Ohno H, Iwanaga $T$. Visualization of the entire differentiation process of murine $M$ cells: suppression of their maturation in cecal patches. Mucosal Immunol. 2015;8:650-60.

47. Wood MB, Rios D, Williams IR. TNF-a augments RANKL-dependent intestinal M cell differentiation in enteroid cultures. Am J Physiol, Cell Physiol. 2016; 311:C498-507.

48. Sun S-C. Non-canonical NF-kB signaling pathway. Cell Res. 2011;21:71-85.

49. Sehgal A, Kobayashi A, Donaldson DS, Mabbott NA. c-Rel is dispensable for the differentiation and functional maturation of $\mathrm{M}$ cells in the follicleassociated epithelium. Immunobiology. 2017;222:316-26.
50. Hase K, Kimura S, Takatsu H, Ohmae M, Kawano S, Kitamura H, Ito M, Watarai H, Hazelett CC, Yeaman C, Ohno H. M-Sec promotes membrane nanotube formation by interacting with Ral and the exocyst complex. Nat Cell Biol. 2009;11:1427-U91.

51. Terahara K, Yoshida M, Igarashi O, Nochi T, Pontes GS, Hase K, Ohno H, Kurokawa S, Mejima M, Takayama N, Yuki Y, Lowe AW, Kiyono H. Comprehensive gene expression profiling of Peyer's patch $M$ cells, villous M-like cells, and intestinal epithelial cells. J Immunol. 2008;180:7840-6.

52. de Lau W, Kujala P, Schneeberger K, Middendorp S, Li VSW, Barker N, Martens A, Hofhuis F, DeKoter RP, Peters PJ, Nieuwenhuis E, Clevers H. Peyer's patch $M$ cells derived from $\mathrm{Lgr5}^{+}$stem cells require SpiB and are induced by RankL in cultured "miniguts". Mol Cell Biol. 2012;32:3639-47.

53. Haber AL, Biton M, Rogel N, Herbst RH, Shekhar K, Smillie C, Burgin G, Delorey TM, Howitt MR, Katz Y, Tirosh I, Beyaz S, Dionne D, Zhang M, Raychowdhury R, Garrett WS, Rozenblatt-Rosen O, Shi HN, Yilmaz O, Xavier RJ, Regev A. A singlecell survey of the small intestinal epithelium. Nature. 2017;551:333-9.

54. Obata T, Goto Y, Kunisawa J, Sato S, Sakamoto M, Setoyama H, Matsuki T, Nonaka K, Shibata N, Gohda M, Kagiyama Y, Nochi T, Yuki Y, Fukuyama Y, Mukai A, Shinzaki S, Fujihashi K, Sasakawa C, lijima H, Goto M, Umesaki Y, Benno $\mathrm{Y}$, Kiyono $\mathrm{H}$. Indigenous opportunistic bacteria inhabit mammalian gut-associated lymphoid tissues and share a mucosal antibody-mediated symbiosis. Proc Natl Acad Sci U S A. 2010;107:7419-24.

55. Sato S, Kaneto S, Shibata N, Takahashi Y, Okura H, Yuki Y, Kunisawa J, Kiyono $H$. Transcription factor Spi-B-dependent and-independent pathways for the development of Peyer's patch M cells. Mucosal Immunol. 2013;6:838-46.

56. Lelouard H, Fallet M, de Bovis B, Méresse S, Gorvel J-P. Peyer's patch dendritic cells sample antigens by extending dendrites through $\mathrm{M}$ cellspecific transcellular pores. Gastroenterology. 2012;142:592-601.e3.

57. Matsumura T, Sugawara Y, Yutani M, Amatsu S, Yagita H, Kohda T, Fukuoka S-I, Nakamura Y, Fukuda S, Hase K, Ohno H, Fujinaga Y. Botulinum toxin A complex exploits intestinal $M$ cells to enter the host and exert neurotoxicity. Nat Commun. 2015;6:6255.

58. Clark MA, Hirst BH, Jepson MA. M-cell surface $\beta 1$ integrin expression and Invasin-mediated targeting of Yersinia pseudotuberculosis to mouse Peyer's patch M cells. Infect Immun. 1998;66:1237-43.

59. Yanagihara S, Kanaya T, Fukuda S, Nakato G, Hanazato M, Wu X-R, Yamamoto $\mathrm{N}$, Ohno H. Uromodulin-SlpA binding dictates lactobacillus acidophilus uptake by intestinal epithelial M cells. Int Immunol. 2017;29:357-63.

60. Kishikawa S, Sato S, Kaneto S, Uchino S, Kohsaka S, Nakamura S, Kiyono H. Allograft inflammatory factor 1 is a regulator of transcytosis in M cells. Nat Commun. 2017:8:14509.

61. Mishima T, Iwabuchi K, Fujii S, Tanaka S-Y, Ogura H, Watano-Miyata K, Ishimori N, Andoh Y, Nakai Y, Iwabuchi C, Ato M, Kitabatake A, Tsutsui H, Onoé K. Allograft inflammatory factor-1 augments macrophage phagocytotic activity and accelerates the progression of atherosclerosis in ApoE $^{-/-}$mice. Int J Mol Med. 2008;21:181-7.

62. Jones BD, Ghori N, Falkow S. Salmonella typhimurium initiates murine infection by penetrating and destroying the specialized epithelial M cells of the Peyer's patches. J Exp Med. 1994;180:15-23.

63. Sansonetti PJ, Arondel J, Cantey JR, Prévost MC, Huerre M. Infection of rabbit Peyer's patches by Shigella flexneri: effect of adhesive or invasive bacterial phenotypes on follicle-associated epithelium. Infect Immun. 1996;64:2752-64.

64. Jensen VB, Harty JT, Jones BD. Interactions of the invasive Pathogens Salmonella typhimurium, listeria monocytogenes, and Shigella flexneri with M cells and murine Peyer's patches. Infect Immun. 1998;66:3758-66.

65. Takakura I, Miyazawa K, Kanaya T, Itani W, Watanabe K, Ohwada S, Watanabe H, Hondo T, Rose MT, Mori T, Sakaguchi S, Nishida N, Katamine S, Yamaguchi T, Aso $\mathrm{H}$. Orally administered prion protein is incorporated by $\mathrm{m}$ cells and spreads into lymphoid tissues with macrophages in prion protein knockout mice. Am J Pathol. 2011:179:1301-9.

66. Donaldson DS, Kobayashi A, Ohno H, Yagita H, Williams IR, Mabbott NA. M cell-depletion blocks oral prion disease pathogenesis. Mucosal Immunol. 2012;5:216-25.

67. Nair VR, Franco LH, Zacharia VM, Khan HS, Stamm CE, You W, Marciano DK, Yagita $H$, Levine B, Shiloh MU. Microfold cells actively translocate Mycobacterium tuberculosis to initiate infection. Cell Rep. 2016;16:1253-8.

68. Kraehenbuhl JP, Neutra MR. Epithelial M cells: differentiation and function. Annu Rev Cell Dev Biol. 2000;16:301-32.

69. Mosca A, Leclerc M, Hugot JP. Gut microbiota diversity and human diseases: should we reintroduce key predators in our ecosystem? Front Microbiol. 2016;7:455. 
70. Nochi T, Yuki Y, Matsumura A, Mejima M, Terahara K, Kim D-Y, Fukuyama S, Iwatsuki-Horimoto K, Kawaoka Y, Kohda T, Kozaki S, Igarashi O, Kiyono H. A novel $\mathrm{M}$ cell-specific carbohydrate-targeted mucosal vaccine effectively induces antigen-specific immune responses. J Exp Med. 2007;204:2789-96.

71. Nochi T, Takagi H, Yuki Y, Yang L, Masumura T, Mejima M, Nakanishi U, Matsumura A, Uozumi A, Hiroi T, Morita S, Tanaka K, Takaiwa F, Kiyono H. Rice-based mucosal vaccine as a global strategy for cold-chain- and needlefree vaccination. Proc Natl Acad Sci U S A. 2007;104:10986-91.

72. Shima H, Watanabe T, Fukuda S, Fukuoka S-I, Ohara O, Ohno H. A novel mucosal vaccine targeting Peyer's patch $\mathrm{M}$ cells induces protective antigenspecific IgA responses. Int Immunol. 2014;26:619-25.

Ready to submit your research? Choose BMC and benefit from:

- fast, convenient online submission

- thorough peer review by experienced researchers in your field

- rapid publication on acceptance

- support for research data, including large and complex data types

- gold Open Access which fosters wider collaboration and increased citations

- maximum visibility for your research: over $100 \mathrm{M}$ website views per year

At BMC, research is always in progress.

Learn more biomedcentral.com/submissions 